\title{
Verticality as the cue for "bigger" in tactile and visual tasks
}

\author{
SHIRLEY W. OSGOOD and GEORGELLE THOMAS \\ Georgia Southern College, Statesboro, Ga. 30458
}

Pairs of three-dimensional objects, equal in volume but differing in height, were presented visually to $105 \mathrm{Ss}$ and tactually to $105 \mathrm{Ss}$ from Grades $1-7$. Ss selected the "bigger" of each pair. Verticality was the dominant visual cue for first and second graders only. In Grades 1-6 verticality was the dominant tactile cue, with some exceptions; seventh graders' choices were a 50-50 split. Results indicated that developmentally verticality remains the dominant cue for "bigger" in the tactile sense longer than in vision.

Some recent investigators have found that children, aged 6 and 7 , choose the taller of two visual displays as "bigger." Lumsden \& Poteat (1968) used planimetric figures equal in area for presentation; Poteat \& Hulsebus (1968) employed three-dimensional figures. Hulsebus (1969), presenting objects visually to Ss in Grades 1-7, found that verticality as a cue for "bigger" decreases in importance as a function of increasing grade level. In another study (Poteat \& Hulsebus, 1968), it was reported that college students are not unduly influenced by verticality in their choice of "bigger," choosing the shorter as frequently as the taller of two visual displays.

The relationship between visual and tactile input has been studied by presenting contradictory sensory material simultaneously (Rock \& Victor, 1963; Rock \& Harris, 1967). Results have consistently indicated the dominance of vision over touch. No studies have been reported, however, in which the importance of a single dimension of concrete objects has been comparatively examined in the visual and tactile senses. That is, the question of whether the vertical dimension is equally important in size judgments in the visual and tactile senses remains unexplored.

The present study compared the role verticality plays when the same task, selecting the "bigger" of two equal-volume objects differing in height, is presented visually and tactually to children in Grades 1-7. Does verticality as a cue for "bigger" diminish in importance as a function of increasing grade levels in tactile tasks as has been reported (Hulsebus, 1969) in visual tasks?

\section{SUBJECTS}

There were 210 Ss from a metropolitan public school. Thirty Ss were randomly selected from each of the seven grades in the school. One-half of the Ss at each educational level were assigned to the visual presentation (VP) group and the other half, to the tactile presentation (TP) group.

\section{MATERIALS}

The apparatus consisted of three stimulus displays, each a pair of wooden three-dimensional objects (rectangles, cones, and cylinders) mounted on a board. Each pair of stimuli was of equal volume but differed in height. The dimensions were as follows: rectangles, $3 \times 3 \times 9$ in. and $4.02 \times 4.02 \times 5$ in.; cones, $5.75 \times 18.25$ in. and $8.24 \times 8.89$ in.; and cylinders, $3 \times 10$ in. and $4 \times 5.63$ in.

The stimulus displays were painted a glossy gray and, for the VP Ss, were presented in front of a dull green backdrop.

Adjustable opaque laboratory goggles were used by the TP Ss.

\section{PROCEDURE}

The same basic procedure was followed in testing both the VP and the TP groups in that all Ss were given three trials, one for each of the stimulus display pairs. The order of display presentation to each $S$ was chosen randomly from 48 different sequences, 24 random order permutations and their reverses.

Ss were seated before a table and told: "Two objects will be placed in front of you. You are to tell me which is bigger. Are there any questions?" As each display was presented, the question, "Which is bigger?" was asked. No judgments of equality were accepted. When a $S$ asked if the display might be ambiguous or if the task could be clarified, the reply was, "Which is bigger to you?"

The only difference in treatment of the groups was that $\mathrm{Ss}$ in the TP group were given goggles to wear after being seated. Instead of visual observation of the displays, their hands were placed on the display bases and they were allowed to explore the objects by touch.

\section{RESULTS}

The salience of the vertical dimension in judgments of "bigger" by the VP and TP groups was examined by chi-square analyses. The computed values are shown in Table 1.

\section{DISCUSSION}

In visual tasks the present results indicate that verticality as a cue for "bigger" diminishes in importance rather quickly as a function of increasing educational level. The taller displays were chosen as "bigger" significantly more often by first and second graders in the VP group; at no other grade level was a significant difference found. This lends support to the Hulsebus (1969) finding that interaction between vertical dimension and grade level decreases with increasing grade level.

With the TP group, different results emerged. Ss in Grades 1.3 chose the taller of each tactually presented stimulus pair as "bigger" significantly more often. In Grades 4,5 , and 6 , choices did not differ from a 50-50 split in the rectangle, cone, and cylinder displays, respectively, although all other display choices at those grade levels did differ significantly in the direction of the taller of each stimulus pair. At the seventh-grade level, the TP group showed no significant preference for the taller of the displays.

The present findings indicate that verticality remains the dominant cue in judgments of "bigger" for a longer time in tactile than in visual tasks. A possible explanation is that the development of the ability to judge volume tactually is slower than the development of the ability to judge it visually. Therefore, young children may erroneously rely more on the verticality of an object when judging it tactually than when judging it visually.

It is possible that some children may interpret "bigger" as "taller," Lumsden \& Kling (1969), in an

Table 1

Chi-Square Analyses to Compare VP and TP Choices of Taller Stimuli

\begin{tabular}{|c|c|c|c|c|c|c|}
\hline \multirow{2}{*}{$\begin{array}{l}\text { Grade } \\
\text { Level }\end{array}$} & \multicolumn{3}{|c|}{ Visual Displays } & \multicolumn{3}{|c|}{ Tactile Displays } \\
\hline & Rectangle & Cone & Cylinder & Rectangle & Cone & Cylinder \\
\hline 1 & $8.07 *$ & $11.27^{*}$ & $11.27^{*}$ & $15.00^{*}$ & $15.00^{*}$ & $15.00^{*}$ \\
\hline 2 & $15.00^{*}$ & $15.00^{*}$ & $15.00 *$ & $8.07^{*}$ & $11.27 *$ & $11.27^{*}$ \\
\hline 3 & 3.27 & .83 & .03 & $15.00^{*}$ & $15.00^{*}$ & $11.27^{*}$ \\
\hline 4 & .60 & .83 & .03 & .83 & $11.27^{*}$ & $8.07^{*}$ \\
\hline 5 & .03 & .83 & .03 & $5.40^{*}$ & 3.27 & $5.40^{*}$ \\
\hline 6 & .83 & .83 & .03 & $8.07 \%$ & $8.07 *$ & .83 \\
\hline 7 & .83 & .03 & 3.27 & 3.27 & .60 & .83 \\
\hline
\end{tabular}

$* p<.05$ for taller stimuli 
attempt to teach children a multidimensional concept of "bigger" described "bigger" to their Ss as the display "that has the most wood in it." In the present study, however, no attempt was made to explain the concept of "bigger" or to determine the Ss' understanding of the word.

Although the importance of verticality as a salient dimension in the young child's judgments of "bigger" has been verified by several investigators (Hulsebus, 1968; Lumsden \& Kling, 1969; Lumsden \& Poteat, 1968; Poteat \& Hulsebus,
1968), a future study is planned in which the stimulus displays will be rotated $90 \mathrm{deg}$. It may be that despite previous interpretations the relevant dimension in children's choosing the "bigger" of two objects is elongation rather than verticality.

\section{REFERENCES}

HULSEBUS, R. C. An interaction between the vertical dimension and age in children's judgments of size. Perceptual Motor Skills, 1969, 28, 841-842.

LUMSDEN, E. A.. JR., KLING, J. K. The relevance of an adequate concept of "bigger" for investigation of size conservation: A methodological critique.
Journal of Experimental Child Psychology, 1969, 8, 82-91.

LUMSDEN, E. A., JR \& POTEAT, B. W. S. The salience of the vertical dimension in the concept of "bigger" in five and six-year olds. Journal of Verbal Learning \& Verbal Behavior, 1968, 7, 404-408.

POTEAT, $B, w, S$ \& HULSEBUS, $R$. $C$. The vertical dimension: A significant cue in the preschool child's concept of "bigger." Psychonomic Science, 1968, 12, 369-370.

ROCK, I., \& HARRIS, C. S. Vision and touch. Scientific American, 1967, 216, 96-104.

ROCK, I., \& VICTOR, J. Vision and touch: An experimentally created conflict between two senses. Science, 1963,143 , 594-596.

\section{CURRENT LITERATURE ON HUMAN VISION}

BARTHOLOMEUS, B. N. (School of Human Communication Disorders, McGill University, Montreal, Canada), \& DOEHRING, D. G. Development of naming responses to meaningful nonverbal sounds. Perceptual and Motor Skills, 1971, 32, 195-204.

BRIGNER, W. L. (Appalachian State University, Boone, N.C. 28607). Role of lateral inhibitory interaction in color coding. Perceptual and Motor Skills, 1971, 32, 451-468.

BRILHART, B. L. (University of Nebrasks at Omaha, Omaha, Nebr. 68105), \& BRILHART, J. K. Field independence and academic achievement of engineering students. Perceptual and Motor Skills, 1971, 32, 443-446.

DAVIS, P. (Medfield Foundation, Medfield, Mass. 02052), \& SILVER, M. J. Ellipse discrimination: A psychophysical task useful for studying incidental stimulation. Perceptual and Motor Skills, 1971, 32, 95-97.

A N D ER S O N, R. H., \& DEF F N B C C ER, K. A. (University of Nebraska at Omaha, Omaha, Nebr. 68101). Effect of sound stimulation on visual afterimages. Perceptual and Motor Skills, 1971, 32, 343-346.
EDWARDS, D. C. (Iowa State University, Ames, Iowa 50010), ANTES, J. R., ADAMS, R. W., \& TRUMM, G. A. Comparison of first-eye-movement detection methods. Perceptual and Motor Skills, 1971, 32, 435-441.

GREGG, L. G. Catholic University of America, Washington, D.C. 20017), \& PASNAK, R. Effects of instructions and training on shape constancy. Perceptual and Motor Skills, $1971,32,485-486$.

HOUCK, R. $\bar{L}$. (Psychiatric and Psychosomatic Research La b or a tory, Veterans Adminsitration Hospital, Houston, Tex. 77031), \& MEFFERD, R. B. Perceptual categorization: Factors influencing identification and reproduction of visual and auditory stimuli. Perceptual and Motor Skills, 1971, 32, 519-522.

IRVING, D. (New School of Behavioral Studies in Education, University of North Dakota, Grand Forks, N. Dak. 58201), \& HENDERSON, D. On the validity of the portable rod-and-frame test. Perceptual and Motor Skills, 1971, 32, 434 .

LAWSON, R. B. (University of Vermont, Burlington, Vt. 05401), \& FREY, W. F. Effects of short-term sensory isolation upon stereoscopic size and distance. Perceptual and Motor Skills, 1971, 32, 571-577.

PRESSEY, A. W. (University of Manitoba, Winnipeg 19, Canada), \& MORO, T. L. An explanation of Cooper and Runyon's results on the Mueller-Lyer illusion. Perceptual and Motor Skills, 1971, 32, 564-566.

SCHNEIDERMAN, D. Z. (Brooklyn College, City University of New York, New York, N.Y. 11210). Tactile-visual perception and cross-modal transfer. Perceptual and Motor Skills, 1971, 32, 159-162.

SIMPSON, W. E. (State University of New York, College at Oswego, Oswego, N.Y. 13126), VAUGHT, G. M., \& HAM, M. L. Intercorrelations among imagery tasks. Perceptual and Motor Skills, 1971, 32, 249-250.

SMITH, G. J. W. (Lund University, Lund, Sweden), \& SJOEHOLM, L. Afterimage change in children following reversal of experimenter's theoretical message. Perceptual and Motor Skills, 1971, 32, 503-509.

WARNER, H. D. (University of Missouri at Rolla, Rolla, Mo. 65401), \& HEIMSTRA, N. W. Effects of intermittent noise on visual search tasks of varying complexity. Perceptual and Motor Skills, 1971, 32, 219-226. 